Research Article

Lina Alhmoud* and Hussein Al-Zoubi

\title{
IoT Applications in Wind Energy Conversion Systems
}

https://doi.org/10.1515/eng-2019-0061

Received May 15, 2019; accepted Sep 27, 2019

\begin{abstract}
Renewable energy reliability has been the main agenda nowadays, where the internet of things (IoT) is a crucial research direction with a lot of opportunities for improvement and challenging work. Data obtained from IoT is converted into actionable information to improve wind turbine performance, driving wind energy cost down and reducing risk. However, the implementation in IoT is a challenging task because the wind turbine system level and component level need real-time control. So, this paper is dedicated to investigating wind resource assessment and lifetime estimation of wind power modules using IoT. To illustrate this issue, a model is built with sub-models of an aerodynamic rotor connected directly to a multi-pole variable speed permanent magnet synchronous generator (PMSG) with variable speed control, pitch angle control and full-scale converter connected to the grid. Besides, a large number of various sensors for measurement of wind parameters are integrated with IoT. Simulations are constructed with Matlab/Simulink and IoT 'Thingspeak' Mathworks web service. IoT has proved to increase the reliability of measurement strategies, monitoring accuracy, and quality assurance.
\end{abstract}

Keywords: Internet of things, Reliability, Sensors, Wind energy, Wind speed.

\section{Introduction}

The Internet is a gigantic intercontinental network of networks. The nodes that comprise each one of these networks were classically used to be computers. Now, with the advent of the Internet of things (IoT), things of the IoT en-

\footnotetext{
^Corresponding Author: Lina Alhmoud: Department of Electrical Engineering,Yarmouk University, Irbid 21163, Jordan; Email: lina.hmoud@yu.edu.jo

Hussein Al-Zoubi: Department of Computer Engineering, Hijjawi Faculty for Engineering Technology, Yarmouk University, Irbid, 21163, Jordan
}

compass any physical entity on earth. Therefore, the Internet is no longer a massive network of computers; but rather the Internet now interconnects heterogenous devices with the required interoperability. This makes these devices (or things) accessible from anywhere on the planet. The user can enjoy the services of these things remotely. Moreover, the operation of these devices can now be controlled remotely via the Internet. It is expected that in the near future, IoT will be so pervasive to cover every aspect of the human's life including renewable energy generation and management.

A distinction between IoT and Cyber-Physical Systems (CPS) has been emphasized though by Lin et al. in [1]. According to Lin et al. [1], IoT is a horizontal architecture providing a networking infrastructure with the main job being interconnection. On the other hand, the CPS is a system consisting of three layers: the Sensor/Actuator layer at the bottom, the Communication Layer as the middle layer, and the application layer at the top. CPS integrates control centers, communication networks, sensors and actuators with the physical components [1].

The things in the IoT generate innumerable amounts of data. The nature of these data is in general unstructured data that need further processing painstakingly. Cloud services, provided by data centers, could be exploited to process such big data [1]. However, this imposes several challenges in case IoT and cloud computing are coupled directly to each other. An exigency shows up to provide a seamless integration, and here comes the role of fog (aka edge) computing. The main purpose of the fog is to move the burden of dealing with vast amounts of data from the cloud to the edge of the IoT, near the end devices. In addition, fog computing is hoped to offer ameliorated security and privacy.

The authors of [2] recounted the hitherto-known software and hardware IoT platforms and compared and contrasted between the various alternatives. The surveyed hardware items included SparkFun Blynk Board, Arduino Yun, Raspberry Pi 3 Board, cloudBit platform, Particle Photon, BeagleBone Black, Pinoccio, UDOO QUAD, and Samsung Artik 10. The basis that one should follow when choosing the right hardware is according to the avail-

๑ Open Access. ( 2019 L. Alhmoud and H. Al-Zoubi, published by De Gruyter. 
able specifications, open API, and open hardware. The compared IoT software platforms encompassed Temboo, Kaa, Carriots, Cayenne, Ubidots, ThingSpeak, Leylan, the ThingBox, Smartliving, Artik Cloud, and Wyliodrin. The choice between the various software platforms should be based on programming IDE, available API, data management tools, and pricing [2].

It is meaningful to investigate wind energy conversion system (WECS) by digital solutions and cybersecurity. In digital renewable energy, data is collected and turned into action by condition monitoring process using machine learning [3]. Cyber-security and their impacts on overall WECS reliability is investigated $[4,5]$. Wind turbine state of the art is analysed using big data for an accurate decisionmaking [6].

To the best of our knowledge, this is the first attempt to employ IoT to enhance the reliability of producing renewable energy from wind turbines. The remainder of this paper is organized as follows. Section 2 presents wind turbine reliability using IoT, followed by siting of wind resource assessment using IoT in Section 3. Reliability calculations and lifetime estimations are addressed in Section 4. This paper finishes with concluding remarks in Section 5.

\section{Wind turbine reliability using IOT}

At the close of 2016, the global cumulative installed wind turbines has reached around $487 \mathrm{GW}$ as shown in Figure 1. USA is considered as the second largest market in terms of total installed capacity after China as shown in Figure 2. IoT has been extended to support applications in energy and power systems including monitoring and control of wind turbines and photovoltaic installations, among others [8]. The purpose of this research is to provide a grander reliability to the operation of wind turbines, as individuals, and to make IoT part of wind farms. Among the aforementioned software alternatives, we have chosen to work with ThinkSpeak in the first phase of our proposed work. ThingSpeak supports Arduino, Particle Photon and Electron, Raspberry Pi, and ESP8266 Wifi Module. ThingSpeak can also update a Twitter status through the ThingTweet App [9].

To provide a real-time monitoring of wind turbine farms and to collect data wirelessly, each turbine within the array can be equipped with its own IoT device [10]. These IoT platforms could be used to report the measured voltage output to develop a power output model of the wind turbine, or what is called the power curve, in addition to the energy analysis for predicting the battery lifetime of

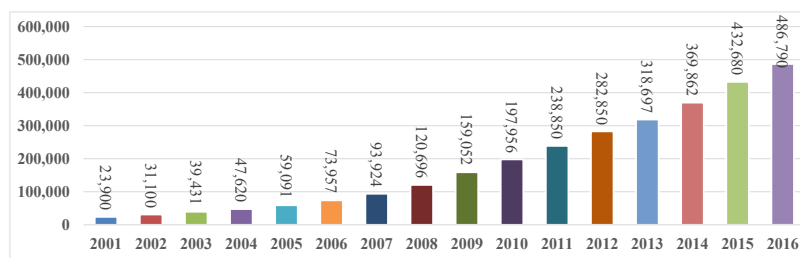

Figure 1: Global Cumulative Installed Wind Capacity 2001-2016 in MW [7].

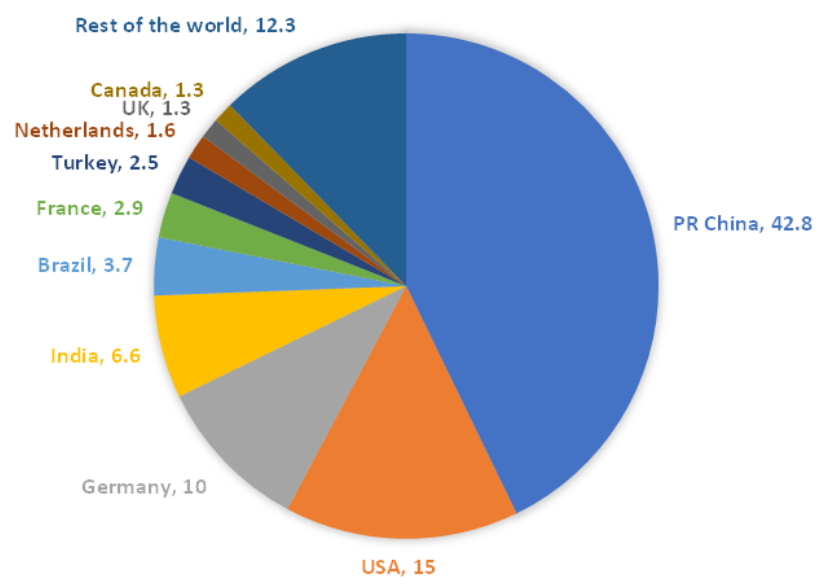

Figure 2: Top 10 new installed capacity Jan-Dec 2016 [7].

the IoT nodes. With the help of IoT, various topics related to wind power generation could be tailored like the interactions across the harmonious wind turbines consituiting the wind farm, exploring various downwind topologies, as well as gingerly ameliorating yaw angles and pitch angles in a periodic fashion. For the purpose of sychronization and archistration between the IoT nodes of the wind farm, the Network Time Protocol (NTP) could be employed. The NTP runs at both the IoT nodes, as well as the web server [10].

Reliability of wind turbines supports a sustainable operation of such an important power source. This mandates real-time monitoring of the wind turbine condition [11] to reduce human intervention as much as possible. To provide an online monitoring and control of the operation of the sensors and actuators of the wind turbine, the IoT provides a promising solution. The proposed system utilizes IoT as shown in Figure 3.

There are several kits that can be utilized to interface wind turbine sensors and actuators at the side of the wind turbine and the Internet and the cloud from the other side. As mentioned earlier, examples include Beagle Bone, Rasberry Pie,... These provide wireless communications with the Internet. The proposed model to utilize IoT in wind energy generation for reliability enhancement is shown in 


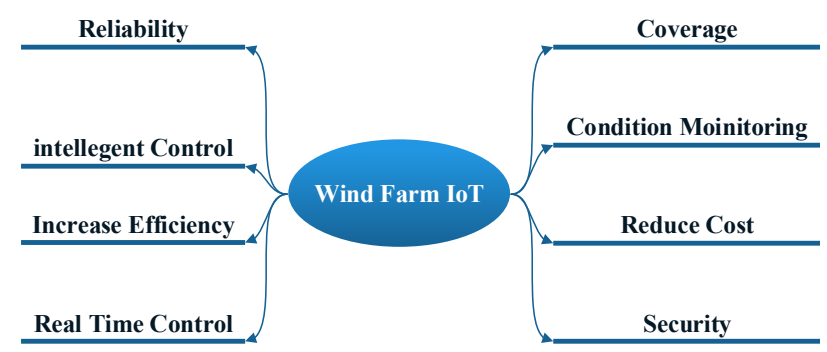

Figure 3: loT features.

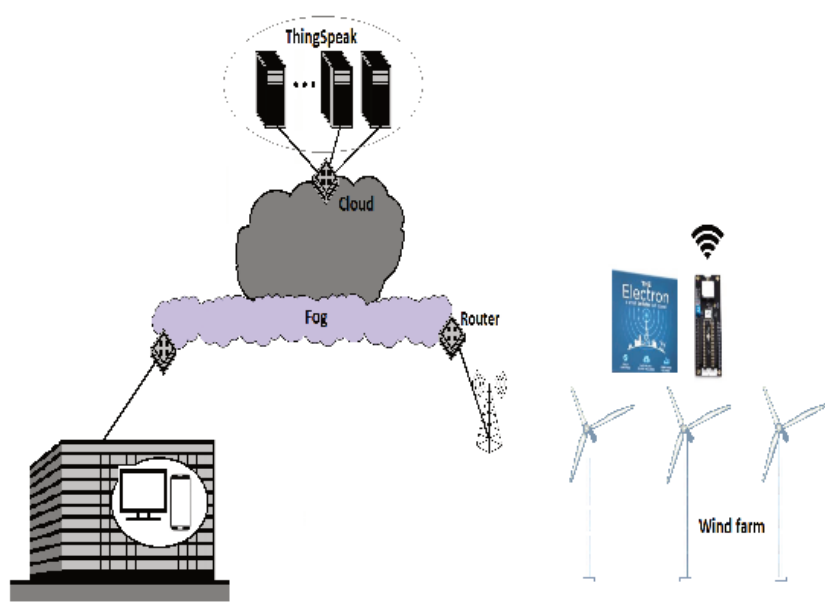

Figure 4: The proposed model to utilize IoT in wind energy generation.

Figure 4. Each wind turbine in the wind farm is equipped with an IoT platform, as the Particle Electron, a cellularconnected microcontroller, that can be directly connected to a cellular network (the operator). The Particle Electron complies with any cellular standard [12]. Then, the wind data is saved and processed on the cloud using Thingspeak [9]. the wind data can be accessed from any where in the world via, say a regular computer or a smart mobile phone, where commands can be directed to the wind farm.

\section{Siting of Wind Resource Assessment Using loT}

IoT plays a significant role in selecting the most suitable location for installing wind turbines. Meteorological sensors will respond to real-time weather conditions, and are designed to monitor specific environmental parameters such as wind speed, wind direction and ambient direction, which are essential for reliability studies as a graphical representation with time. The core of wind turbine reliability assessment depends on the accuracy of wind mis- sion profile measurements [13]. Through IoT, automated historical data besides daily work reports can be obtained to enhance long-term reliability, optimize operations in long-term and increase annual energy production. Future wind turbines will be self organized owe to sensors and implementation control strategies using IoT, so they can optimize themselves at any point with any given condition thrown on them. The best wind resource is obtained when the weather is cold, but icing on the blades of wind turbines can reduce energy production by up to $20 \%$ [14]. In addition, it may cause spinning on the nacelle leading to mechanical fatigue which causes shaft cracks, tooth breakage, shattering, damage to the tower and reduction in reliability [15]. These undesirable events lead to smart de-icing systems to take place in freezing weather, hence IoT combines sensors and database. In case the output energy is too low, the more reliable decision will be made by IoT to continue running or shut down and throw the ice around using a heating system and an additional small fan built on the blades. Other techniques used to keep the turbine rotor running smoothly and to prevent ice from gradually increasing include acceleration or deceleration of the rotating blades to shake them, or using water resistant coatings.

Investigating the availability of wind resources is important for wind turbine installation and for predicting performance in order to quantify the overall reliability, performance and wind turbine energy output. Wind dialogue gives us an accurate, real time view of the operational status of our input wind mission profile. In addition to that it allows quick access to wind parameters reports. Wind turbines can be monitored through sensors to track air flow and mechanical power that will be extracted from wind. Where sensors highness, location, accuracy, duration, quality and quantity should be considered. Moreover, better IoT performance depends on trusted and identified measures including data sampling, recording, handling, recovery, quality, quantity and format, which should all be taken into account. We have carried out these steps using IoT to maintain reliability performance within a scheduled plan [16]. As sensor technology advances, it becomes possible to monitor wind turbines on wind farms, ensuring maximization of air flow and mechanical power. Wind turbines are highly optimized to their future needs through continuous, smooth collection of high quality data, which is measured using the proposed model in terms of representativeness, accuracy, and completeness. Using IoT, the operator can compare between ideal and actual performance of technical issues, and identify the root causes of the two cases to recommend individual and sustainable solutions for these technical issues of wind turbines by pre- 


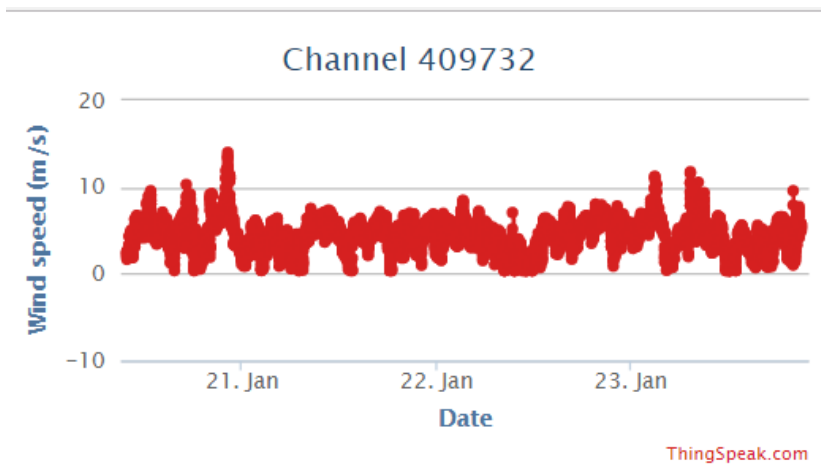

Figure 5: Wind speed using loT.

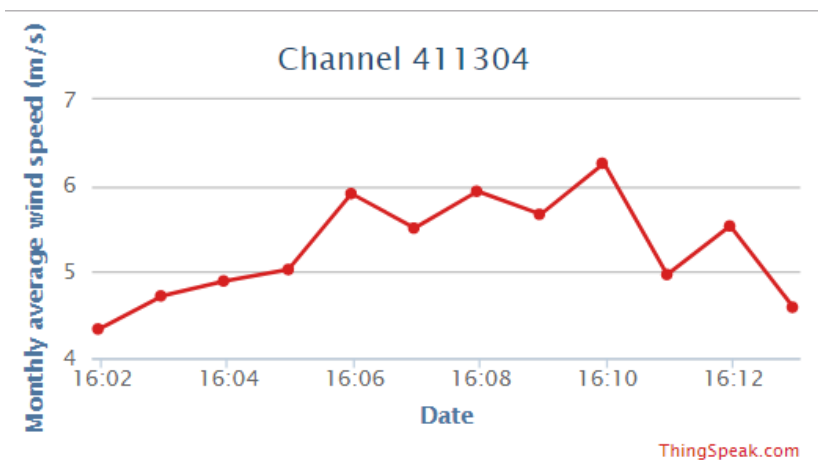

Figure 6: Monthly average wind speed using loT.

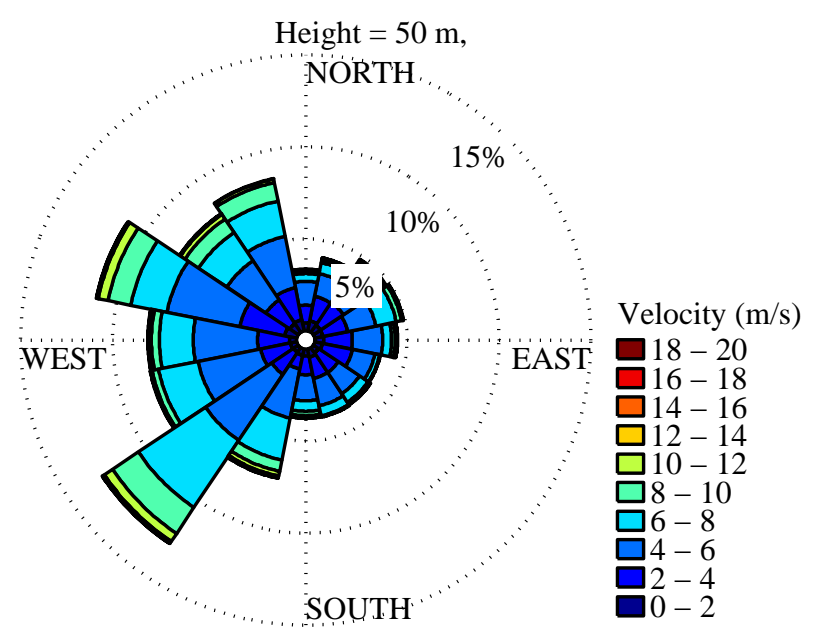

Figure 7: Wind rose

dicting components failures, and optimize maintenance schedules, which will drive down the cost of operating wind turbines.

Many important indicators of a wind farm operating environment such as wind speed and monthly average wind speed are plotted by IoT as shown in Figures 5 and 6 . In addition, wind rose is an important graphical representation that gives information about how wind speed and di-

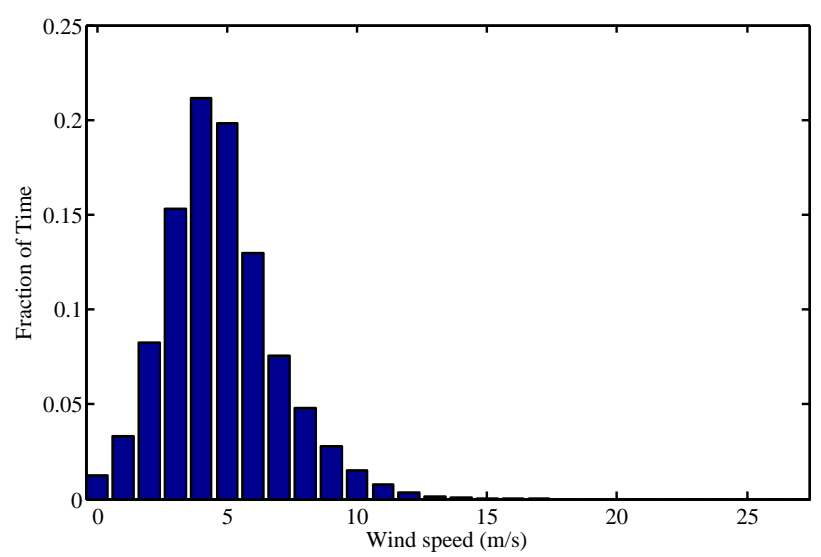

Figure 8: Wind speed distribution

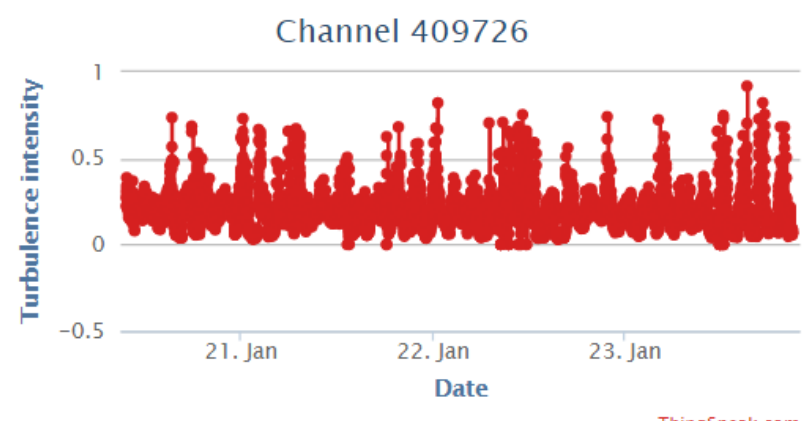

Figure 9: Turbulence intensity using loT.

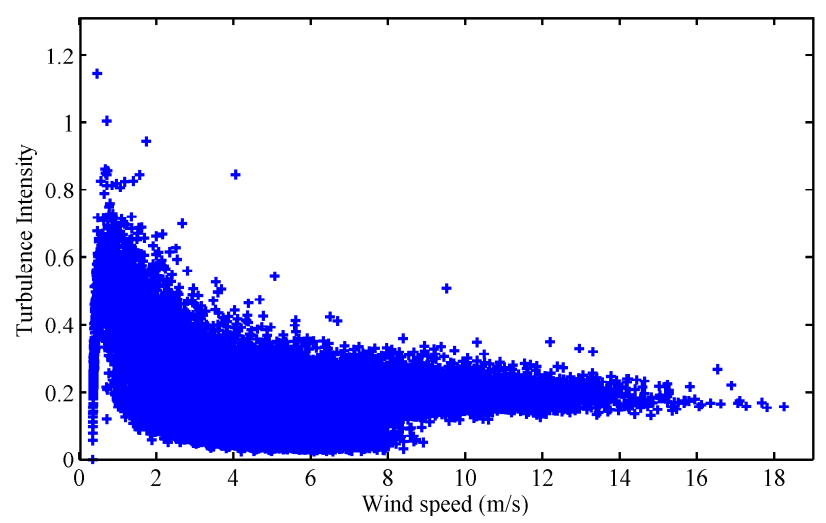

Figure 10: Turbulence intensity

rection are typically distributed as shown in Figure 7. Wind speed distribution shows a frequency of winds over time as shown in Figure 8. In wind turbine siting, the turbulence intensity (TI) indicator is a very important factor. TI normalizes the standard deviation $(\sigma)$ of wind speed with the mean wind speed as shown in Figures 9 and 10. TI is defined as

$$
T I=\frac{\sigma}{V}
$$




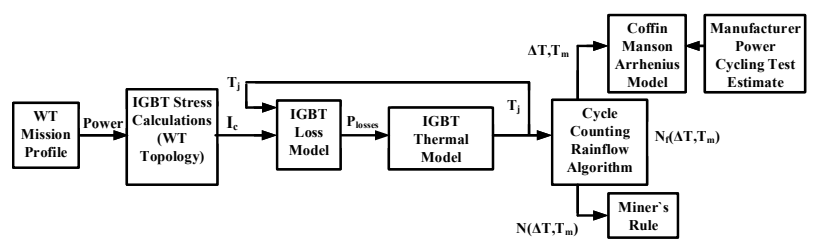

Figure 11: Lifetime estimation model for power semiconductor devices.

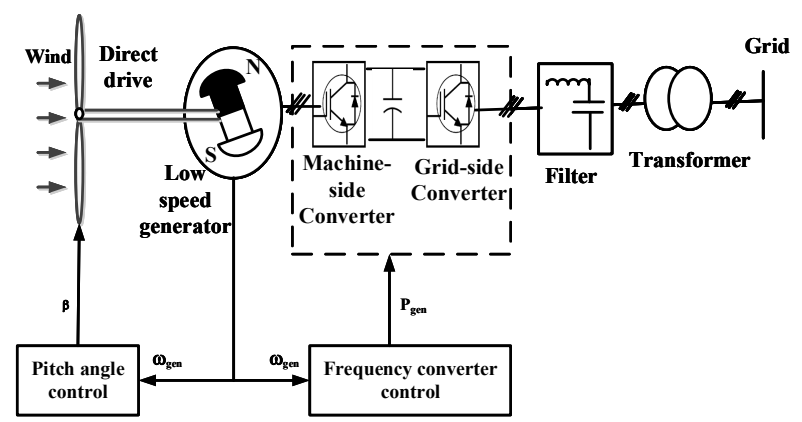

Figure 12: System under study.

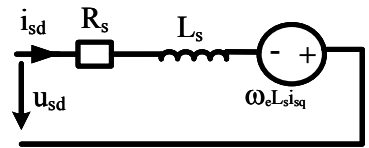

d- axis circuit

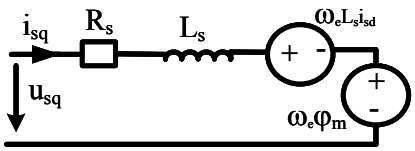

q-axis circuit
Figure 13: Equivalent circuit of permanent magnet synchronous generator [19].

where $\sigma$ is the standard deviation of wind speed; and $V$ is the mean wind speed. When $T I<0.1$ is considered as a low level, $0.1<T I<0.25$ it is a moderate level of turbulence and $T I>0.25$ is a high level.

\section{Reliability Assessment}

\subsection{Model Integration}

Similar to our previous work [16], the prediction of power cycling lifetime for machine side converter control in PMSG is examined. To handle this issue, A PMSG with a drive train model as shown in Figure 14 connected to a control strategy for the turbine pitch angle $\beta$ as shown in Figure 15 are considered. A comprehensive thermal model for the power IGBT modules used in three-phase converter has been built to predict the dynamic junction temperature rise. To perform a real and complete thermal model as shown in Figure 11, a faster power modules loss prediction method was proposed based on lookup tables, and the required parameters were obtained from the Semikron
Table 1: Aerodynamic Parameters

\begin{tabular}{cc}
\hline Nominal turbine power $P_{n}$ & $1.5 \mathrm{MW}$ \\
\hline Turbine rotor radius $R$ & $72 \mathrm{~m}$ \\
Rated wind speed & $16 \mathrm{~m} / \mathrm{s}$ \\
Cut-in wind speed & $7 \mathrm{~m} / \mathrm{s}$ \\
Cut-out wind speed & $22 \mathrm{~m} / \mathrm{s}$ \\
Air density $\rho$ & $1.1225 \mathrm{~kg} / \mathrm{m}^{3}$ \\
\hline
\end{tabular}

Table 2: PMSG Parameters

\begin{tabular}{cc}
\hline Generator type & Multi pole PMSG \\
\hline Power $P$ & $1.5 \mathrm{MW}$ \\
Stator voltage $V_{s n}$ & $575 \mathrm{~V}$ \\
No. of pole pairs & 48 \\
Dynamic speed range $n_{m}$ & $7-22 \mathrm{rpm}$ \\
Mechanical frequency $f_{m}$ & $0.1167-0.367 \mathrm{~Hz}$ \\
Electrical frequency $f_{e}$ & $5.6-17.6 \mathrm{~Hz}$ \\
Stator phase resistance $R_{S}$ & $0.006 \Omega$ \\
Armature inductance $L$ & $0.000835 \mathrm{H}$ \\
Flux linkage established by & $1.48 \mathrm{~V} \cdot \mathrm{s}$ \\
magnets $\lambda$ & \\
Generator rotor inertia $J_{G}$ & $35000 \mathrm{~kg} \cdot \mathrm{m}^{2}$ \\
Generator rotor self-damping $D_{G}$ & $0.01 \mathrm{~N} \cdot \mathrm{m} \cdot \mathrm{s}$ \\
Rated grid voltage & $5.6 \mathrm{kV}$ \\
\hline
\end{tabular}

IGBT module SKiiP2013 GB172-4DW. This data sheet is designed for wind turbine applications. Then an equivalent RC network model is built with parameters obtained from the same manufactures' datasheet as shown in Figure 18 and Table 4. Hence,the Lifetime is estimated based on the behavior of the semiconductor devices under their mission profile.

A demonstration of the system under study is shown in Figure 12, which shows wind turbine aerodynamics, and topographic effects of wind speed, direction and ambient temperature that are combined with multi-pole space, direct driven, variable-speed permanent magnet synchronous generator (PMSG). The wind turbine is connected to the grid via frequency converter with a DC-link capacitor [17][18]. The main feature of PMSG is that there is no need to external excitation current [19]. The parameters of the system under study are listed in Tables 1, 2 and 3. A Steady state voltage in $d-q$ rotor-oriented reference frame is shown in Figure 13, with:

$$
\begin{aligned}
& V_{q s}^{r}=R_{q} i_{q s}^{r}+p \lambda_{q s}^{r}+\omega_{r} \lambda_{d s}^{r} \\
& V_{d s}^{r}=R_{d} i_{d s}^{r}+p \lambda_{d s}^{r}-\omega_{r} \lambda_{q s}^{r}
\end{aligned}
$$


where $R_{d}, R_{q}$ are stator $\mathrm{d}$ and $\mathrm{q}$ axis winding resistance, respectively, $\Omega . i_{d s}, i_{q s}$ are stator $\mathrm{d}$ and $\mathrm{q}$ axis currents, respectively, A. $\lambda_{d s}, \lambda_{q s}$ are stator $\mathrm{d}$ and $\mathrm{q}$ axis flux linkage, respectively, V.s. $\omega_{r}$ is the electrical rotor speed, $\mathrm{rad} / \mathrm{s}$. And $p$ is the differential operator.

Equations (4) and (5) are the stator flux linkages:

$$
\begin{aligned}
& \lambda_{q s}^{r}=L_{s} i_{q s}^{r}+L_{m}^{r} i_{q r}^{r} \\
& \lambda_{d s}^{r}=L_{s} i_{d s}^{r}+L_{m}^{r} i_{d r}^{r}
\end{aligned}
$$

where $L_{s}$ is stator self inductance per phase, H. $i_{d r}, i_{q r}$ are rotor $\mathrm{d}$ and $\mathrm{q}$ axis currents, respectively, A. $L_{m}$ is magnetization inductance per phase, $\mathrm{H}$. And $P$ is number of poles The electromagnetic torque is given by Equation (6)

$$
T_{e}=\frac{3}{2} \frac{P}{2}\left\{\lambda_{d s}^{r} i_{q s}^{r}+\lambda_{q s}^{r} i_{d s}^{r}\right\}
$$

And the active power $P_{g e n}$ and the reactive power $Q_{g e n}$ of PMSG can be expressed as shown in Equations (7) and (8), respectively:

$$
\begin{gathered}
P_{\text {gen }}=T_{e} \omega_{m}=\frac{3}{2}\left[V_{d s}^{r} i_{d s}^{r}+V_{q s}^{r} i_{q s}^{r}\right] \\
Q_{g e n}=\frac{3}{2}\left[V_{q s}^{r} i_{d s}^{r}-V_{d s}^{r} i_{q s}^{r}\right]
\end{gathered}
$$

The control of PMSG is done in rotor reference frame and the machine side converter is controlled through a PI controller, where minimum current is obtained through d-axis and current is held to zero to have a maximum torque. The grid side converter is explored through a hysteresis controller. A direct coupled PMSG in wind turbines eliminates the need of gear box as shown in Figure 14. The turbines are allowed to perform their best by adjusting their blade pitch angle as shown in Figure 15 by managing the impacts of unpredictable wind speed.

\subsection{Converter Power Loss Estimation}

PMSG is connected to fixed frequency grid via a variable frequency converter as shown in Figure 16. The rotational speed $\omega_{m}$ varies between $7-22 \mathrm{rpm}$ depending on the wind speed. Therefore, the corresponding mechanical frequency $f_{m}$ varies between $0.1167 \mathrm{~Hz}$ and $0.367 \mathrm{~Hz}$. The electrical frequency generated by PMSG is determined by Equation (9)

$$
f_{e}=f_{m} P
$$

where $f_{m}$ is the mechanical frequency and $P$ is the number of pole pairs. The averaged model of three-phase backto-back (PWM) converter is adopted in this work as shown

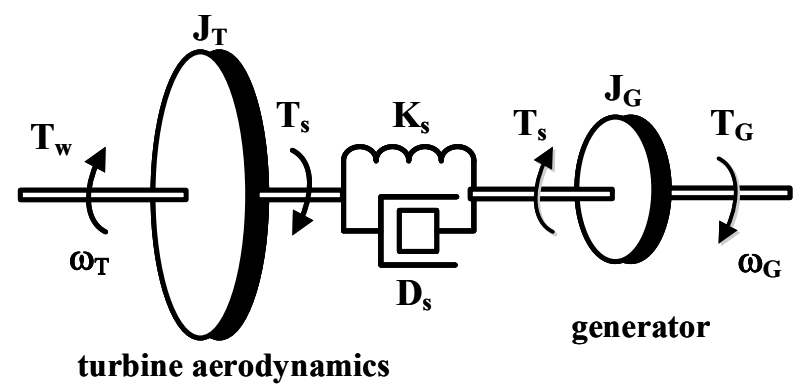

Figure 14: Drive train model [20].

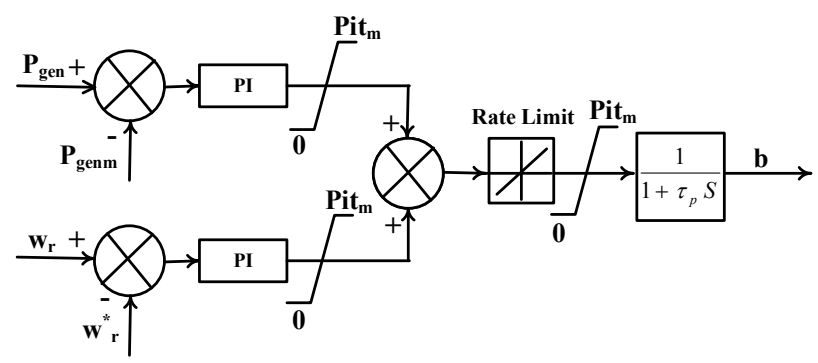

Figure 15: Control strategy for the turbine pitch angle $\beta$ [21].

Table 3: $D C$-link Parameters

\begin{tabular}{cc}
\hline dc-bus capacitor $C_{d c-l i n k}$ & $10000 * 10^{-6} \mathrm{MW}$ \\
\hline Nominal dc-link voltage $V_{d c}$ & $1150 \mathrm{~V}$ \\
Coupling inductor of GSC $L$ & $0.3 \mathrm{pu}$ \\
Coupling resistance of $G S C R$ & $0.003 \mathrm{pu}$ \\
Frequency of the GSC $P W M$ carrier & $2700 \mathrm{~Hz}$ \\
Frequency of the $R S C$ PWM carrier & $1620 \mathrm{~Hz}$ \\
DC bus voltage regulator gains $\left[K_{p}\right.$ & {$[8400]$} \\
$\left.K_{I}\right]$ & \\
\hline
\end{tabular}

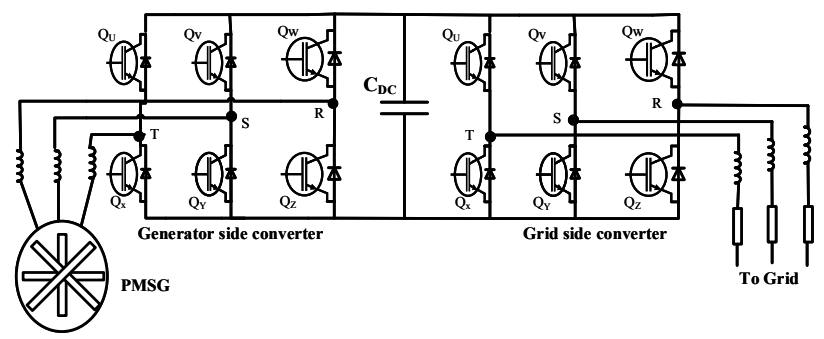

Figure 16: Frequency converter.

in Figure 16. It is suitable for wind application and especially for computer simulation. It makes the simulation run faster with less complexity and acceptable accuracy for obtaining the converter losses. In the following, we show basic equations for calculating the conduction and switching losses based on Figure 17. Switching losses $P_{S V}$ 


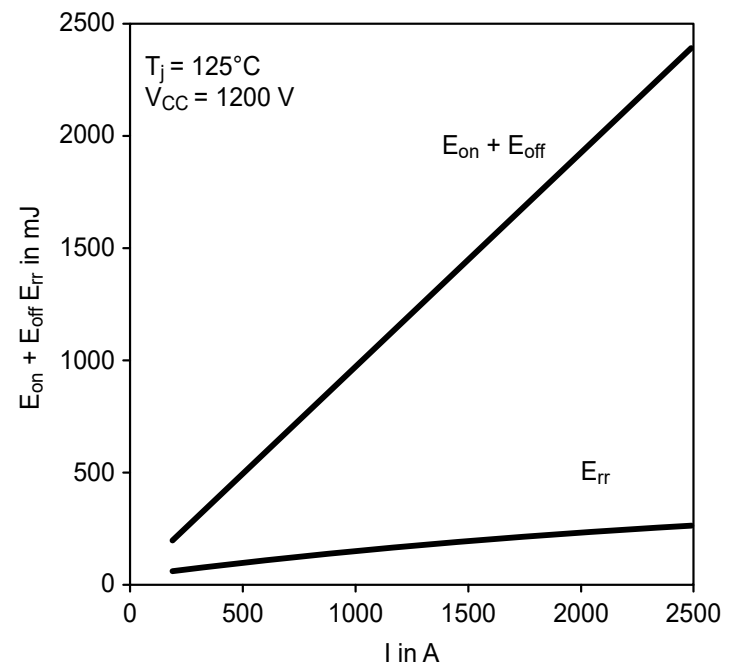

Figure 17: Typical energy losses $E=f\left(I_{c}, V_{c c}\right)[30]$.

of VSC is given by Equation (10) [30].

$$
P_{s w}=\frac{6}{\pi} \cdot f_{s} \cdot\left(E_{\text {ON.I }}+E_{\text {OFF.I }}+E_{\text {OFF.D }}\right) \cdot \frac{V_{d c}}{V_{\text {ref }}} \cdot \frac{\hat{i}_{L}}{i_{\text {ref }}}
$$

where $f_{s}$ is the switching frequency, $E_{O N . I}$ and $E_{O F F . I}$ are the turn on and turn off energies of the IGBT, respectively. $E_{\text {off. } . D}$ is the turn off energy in the power modules' diode due to reverse recovery current. $V_{d c}$ is the dc link voltage. $\hat{i_{L}}$ is the peack value of ac line current. $V_{\text {ref }}$ and $i_{\text {ref }}$ are the reference values given in the data sheet [22]. Conduction losses of a single IGBT $P_{C V . I}$ is expressed by Equation (11) and conduction losses in diode $P_{C V . D}$ ares expressed by Equation (12).

$$
\begin{aligned}
P_{C V . I} & =\frac{V_{C E} \cdot \hat{i}_{L}}{2 . \pi} \int_{0}^{\pi} \sin (\omega t) \cdot \frac{1+M(t)}{2} \cdot d \omega t \\
& +\frac{r_{C E} \cdot \hat{i}_{L}^{2}}{2 . \pi} \int_{0}^{\pi} \sin ^{2}(\omega t) \cdot \frac{1+M(t)}{2} \cdot d \omega t \\
P_{C V . D} & =\frac{V_{F} \cdot \hat{i}_{L}}{2 . \pi} \int_{0}^{\pi} \sin (\omega t) \cdot \frac{1-M(t)}{2} \cdot d \omega t \\
& +\frac{r_{F} \cdot \hat{i}_{L}^{2}}{2 . \pi} \int_{0}^{\pi} \sin ^{2}(\omega t) \cdot \frac{1-M(t)}{2} \cdot d \omega t
\end{aligned}
$$

where $\omega$ is the load current's angular frequency, $\mathrm{M}(\mathrm{t})$ is the modulation function, $V_{C E}$ is the IGBT's threshold voltage, $r_{C E}$ is the IGBT's differential resistance, $V_{F}$ and $r_{F}$ are the diode's threshold voltage and differential resistance, respectively. The total converter power losses is given by Equation (13).

$$
P_{C V}=6 .\left(P_{C U . I}+P_{C U, D}\right)
$$

\subsection{Electrothermal Model}

Different techniques have been used to perform the electrothermal analysis; such as analytical, numerical, and behavioral [24]. Thus, numerical methods are used to solve the equations governing the conservative of mass and momentum as computational fluid dynamic (CFD) [25]. Besides, the finite element method (FEM) and finite difference method (FDM) are used for the discretization of the differential equation for heat conduction [26]. In this work, Analytical methods are selected to predict the operating temperature of semiconductor devices[27]. These methods provide better physical insight by use of a physical model. $\mathrm{RC}$ ladder networks are commonly adopted for thermal analysis since they are ready to be integrated into existing circuit simulator and are capable of simulating both electrical and thermal characteristics. Over that, RC thermal model can be implemented in the real-time simulation due to its easy implementation and simple computational [28]. Once the power dissipated in the IGBT power converters has been calculated, this power is used as excitation current source in a thermal model as shown in Equations (14-17) to estimate junction temperature of the operational IGBT's.

$$
\begin{gathered}
\dot{x}=A x+B u \quad\left[{ }^{\circ} C / \Delta t\right] \\
y=C x+D u \quad\left[{ }^{\circ} C\right] \\
Y / u=C(s I-A)^{-1} B+D \quad\left[{ }^{\circ} C / W\right] \\
Z_{j c}(t)=\frac{T_{j}(t)-T_{c}(t)}{P}=\frac{\Delta T_{j c}(t)}{P}
\end{gathered}
$$

where

$$
\begin{aligned}
& A=\left[\begin{array}{cccc}
\frac{-1}{R_{2} C_{1}} & \frac{1}{R_{2} C_{1}} & 0 & 0 \\
\frac{-1}{R_{2} C_{2}} & \left(\frac{-1}{R_{2} C_{2}}-\frac{1}{R_{3} C_{2}}\right) & \frac{1}{R_{3} C_{2}} & 0 \\
0 & \frac{1}{R_{3} C_{3}} & \left(\frac{-1}{R_{3} C_{3}}-\frac{1}{R_{4} C_{3}}\right) & \frac{1}{R_{4} C_{3}} \\
0 & 0 & \frac{-1}{R_{4} C_{4}} & \left(\frac{-1}{R_{4} C_{4}}-\frac{1}{R_{5} C_{4}}\right)
\end{array}\right] \\
& B=\left[\begin{array}{llll}
\frac{1}{C_{1}} & 0 & 0 & 0
\end{array}\right]^{T}, C=\left[\begin{array}{llll}
1 & 0 & 0 & 0
\end{array}\right]^{T}, \text { and } D=R_{1} .
\end{aligned}
$$

The power losses and the operational temperatures are related by the thermal impedance as shown in Figure 18. A Semikron IGBT module SKiiP2013 GB172-4DW, which has the characteristics shown in Table 4, is designed for wind turbine applications. This IGBT module is used in this paper to construct the electrothermal model of the power devices. The values of the thermal impedances have been extracted from the dynamical thermal impedance curve from the manufacturers̀ datasheet, as given in Table 5 . 
Table 4: Component (type) Designation System.

\begin{tabular}{lcccc}
\hline $\begin{array}{l}\text { Case } \\
\text { form }\end{array}$ & $\begin{array}{c}\text { Current } \\
\text { grade }(\& \\
\text { case size })\end{array}$ & $\begin{array}{c}\text { Circuit } \\
\text { abbreviation }\end{array}$ & $\begin{array}{c}\text { Blocking } \\
\text { voltage } \\
(\star 100 V)\end{array}$ & Chip \\
\hline SKiiP & 1814 & GB & 17 & E4 \\
\hline
\end{tabular}

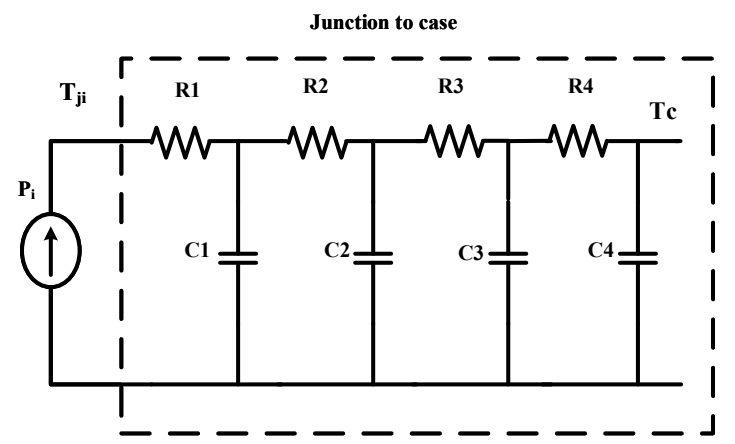

Figure 18: Cauer thermal impedance between the junction temperature and case layer.

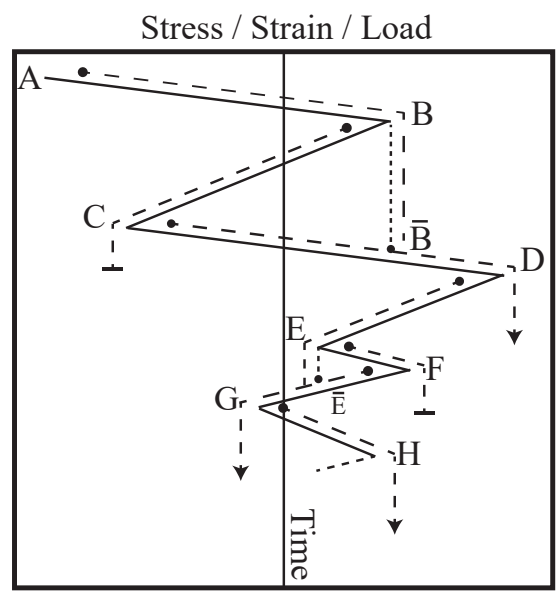

Figure 19: Example of rainflow algorithm

\subsection{Lifetime Estimation}

Lifetime is considered as an important statistical indicator. The estimation of lifetime is based on how long the product is expected to perform its function under certain electrical, mechanical and thermal conditions. In literature, there are many counting methods for lifetime estimation for power modules that are used to extract amplitude and number of thermal cycles from a mission profile [31, 32, 32]. Unfortunately, these methods cannot capture accurately all the characteristics needed for reliability assessment. In this work, the Rainflow cycle counting method, which was developed in 1968 by Endo and Matsuishi is applied as shown in Figure 19. Various failure modes for IGBT modules are es-

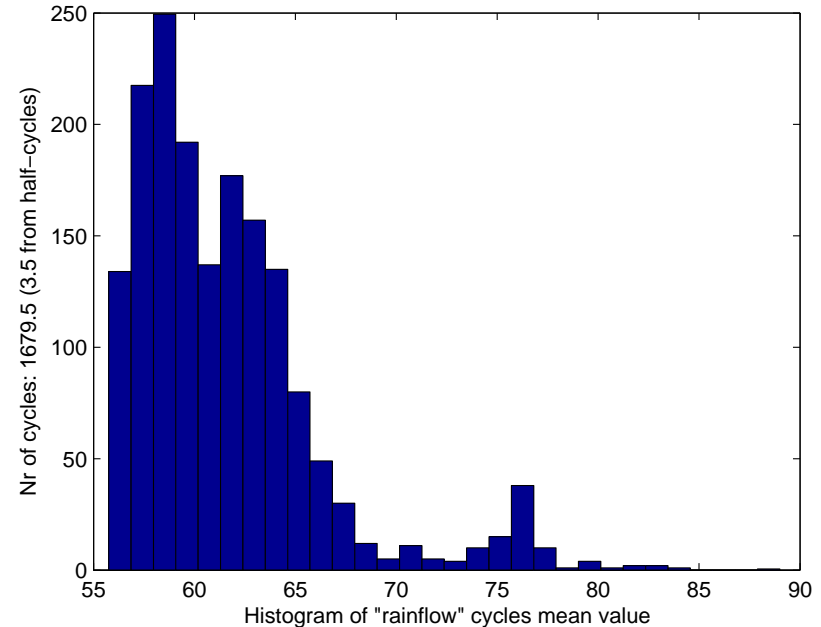

Figure 20: Mean temperature value $T_{m}$ extracted from the rainflow counting algorithm.

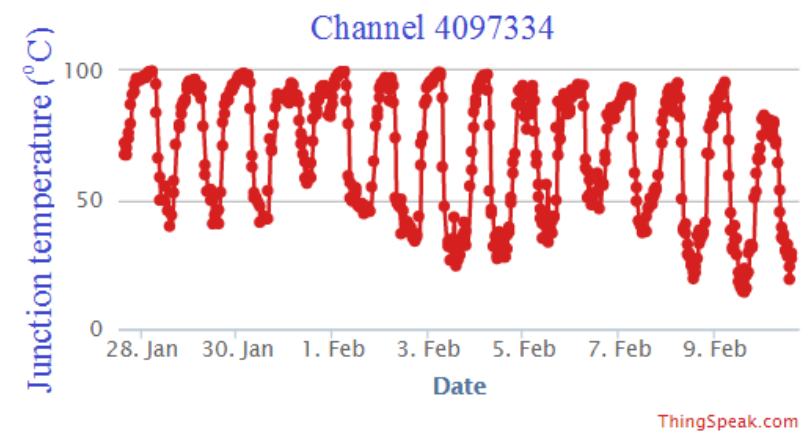

Figure 21: Junction temperature $\left({ }^{\circ} \mathrm{C}\right)$

sential to understand the failure mechanism to predict the power converter lifetime [29]. An improved lifetime model was obtained from [30] as shown in Equation (18) and the parameters are listed in Table 6.

$$
N_{f}=A \cdot \Delta T_{j}^{\beta_{1}} \cdot \exp \left(\frac{\beta_{2}}{T_{j . \min }+273}\right) \cdot t_{o n}^{\beta 3} \cdot I_{B}^{\beta 4} \cdot V_{C}^{\beta 5} \cdot D^{\beta 6}
$$

Figure 20 shows the frequency distribution of temperature cycles defined by their mean temperature value $T_{m}$ extracted from the rainflow counting algorithm with 1697.5 cycles. IGBT junction temperature variations is uploaded with IoT 'Thingspeak' Mathwork web service and shown in Figure 21. The analysis shows that the lifetime is heavily influenced by thermal cycling, and these thermal cycles lead to a degradation of the wire bonds. Lifetime of IGBT power module is estimated around 14521 hours. 
Table 5: Thermal Impedance of Cauer Network

\begin{tabular}{ccccccc}
\hline$R_{t h}[K / W]$ & 1 & 2 & 3 & 4 & 5 & 6 \\
\hline$Z_{t h}(j-r)$ & 0.0011 & 0.0059 & 0.0063 & 0.0021 & 0.0021 & 0.0000 \\
$Z_{t h}(r-a)$ & 0.0002 & 0.0012 & 0.0042 & 0.0034 & 0.0002 & 0.0000 \\
\hline \hline$\tau[s]$ & 1 & 2 & 3 & 4 & 5 & 6 \\
\hline$Z_{t h}(j-r) I$ & 0.0007 & 0.0268 & 0.2165 & 1.0453 & 2.2456 & 1.0000 \\
$Z_{t h}(r-a)$ & 0.1382 & 1.4254 & 8.3077 & 20.093 & 189.77 & 1.0000 \\
\hline
\end{tabular}

Table 6: Parameters and limits for the calculation of power cycles using equation in (18)

\begin{tabular}{cccccc}
\hline Parameters & Symbol & Unit & Limits & Coefficient & Value \\
\hline Technology factor & $\mathrm{A}$ & - & - & - & $9.34 \mathrm{E}+14$ \\
Temperature difference & $\Delta T$ & $\mathrm{~K}$ & $45 \ldots 150$ & $\beta_{1}$ & -4.416 \\
Min. chip temperature & $T_{j(\mathrm{~min})}$ & ${ }^{\circ} \mathrm{C}$ & $20 \ldots 120$ & $\beta_{2}$ & 1285 \\
Pulse duration & $t_{o n}$ & $\mathrm{~S}$ & $1 \ldots 15$ & $\beta_{3}$ & -0.463 \\
Current per bond foot & $I_{B}$ & $\mathrm{~A}$ & $3 \ldots 23$ & $\beta_{4}$ & -0.716 \\
Voltage class $/ 100$ & $V_{c}$ & $\mathrm{~V}$ & $6 \ldots 33$ & $\beta_{5}$ & -0.761 \\
Bond wire diameter & $\mathrm{D}$ & $\mu m$ & $75 \ldots 500$ & $\beta_{6}$ & -0.5 \\
\hline
\end{tabular}

\section{Conclusions}

Wind energy resource assessment and reliability performance have been estimated using IoT, where mission profile should be monitored, analyzed and controlled in real time. Then, a comprehensive thermal model is developed in three steps: the power losses are calculated; then the junction temperatures are evaluated and the lifetime is estimated.

Therefore, the main purpose of this paper is to estimate a reliability model of PMSG using 'Thingspeak' Mathworks web service. So, due to long operation hours under challenging environments, wind turbines can meet with their main technological advancement through IoT. This will grant field operators the tools to ensure maintenance strategy development, reduce uncertainty, maintain system reliability and availability and enhance annual energy production. In addition, wind farm operators expect industrial strength with global scalability and significant benefits from IoT implementation and evaluation such as gathering data to seek performance optimization, instrumenting wind farm with sensors, identifying predictive and preventive maintenance and connecting system level and component level together through IoT. On the other hand, lack of budget and lack of skills are considered main barriers for releasing IoT in wind farms, besides security concerns, communication protocols, limiting devices access to internet, time pressure and lack of priority. We plan to address these issues in our future work. Furthermore, we plan to use the Particle Electron for data acquisition.

\section{References}

[1] Lin J., Yuy W., Zhangz N., Yang X., Zhangx H., and Zhao W., A Survey on Internet of Things: Architecture, Enabling Technologies, Security and Privacy, and Applications, IEEE Internet of Things Journal, 2017, 4(5), 1125-1142.

[2] Singh K. J. and Kapoor D. S., A survey of IoT platforms, Create Your Own Internet of Things, IEEE Consumer Electronics Magazine, 2017, (4), 57-68.

[3] Arcos J., Alfredo C., Quiterio G. M., and Fausto P. G. M., Machine Learning for Wind Turbine Blades Maintenance Management, Energies, 2017, 11.1, 13.

[4] Zhang Y., Yingmeng X., and Lingfeng W., Power system reliability assessment incorporating cyber attacks against wind farm energy management systems, IEEE transactions on smart grid, 2017, 8.5, 2343-2357.

[5] Hatzivasilis G., Konstantinos F., Othonas S., Ioannis A., Ioannis P., Giorgos D., The Industrial Internet of Things as an enabler for a Circular Economy Hy-LP: A novel IloT protocol, evaluated on a wind parks SDN/NFV-enabled 5G industrial network, Computer Communications, 2018, 119, 127-137.

[6] Pliego, Alberto, Raul Ruiz de la Hermosa, and Fausto Pedro Garcia Marquez. "Big Data and Wind Turbines Maintenance Management." Renewable Energies. Springer, Cham, 2018, 111-125.

[7] Global Wind Energy Council, Global Wind Report 2016-Annual Market Update. 2016.

[8] Bedi G., Venayagamoorthy G. K. and Singh R. , Navigating the Challenges of Internet of Things (IoT) for Power and Energy Systems, Clemson University Power Systems Conference (PSC), 
2016,1-5.

[9] ThingSpeak. [Online] https://thingspeak.com/

[10] Srbinovski B., Conte G., Morrison A. P., Leahy P., and Popovici E., ECO: An loT platform for wireless data collection, energy control and optimization of a miniaturized wind turbine cluster: Power analysis and battery life estimation of IoT platform. 2017 IEEE International Conference on Industrial Technology (ICIT). IEEE, 2017,412-417.

[11] Moness M. and Moustafa A., A Survey of Cyber-Physical Advances and Challenges of Wind Energy Conversion Systems:Prospects for Internet of Energy, IEEE Internet of Things Journal, 2016, 3(2), 134-145.

[12] Particle. [Online] https://www.particle.io/

[13] Lun, Y. F., Mochida, A., Murakami, S., Yoshino, H., and Shirasawa, T., Numerical simulation of flow over topographic features by revised $k^{\longleftarrow} \epsilon$ models, Journal of Wind Engineering and Industrial Aerodynamics, 2003, 91(1-2), 231-245.

[14] engineering.com. [Online] https://www.engineering.com/

[15] Alhmoud, L., and Wang B., A review of the state-of-the-art in windenergy reliability analysis, Renewable and Sustainable Energy Reviews 2018,81, 1643-1651.

[16] Alhmoud L.,Reliability improvement for high-power IGBT in wind energy applications, IEEE Transactions on Industrial Electronics, 2018, 65.9, 7129-7137.

[17] Pravica, L., Sumina, D., Barisa, T., Kovacic, M., and Colovic, I, Flying Start of a Permanent Magnet Wind Power Generator Based on a Discontinuous Converter Operation Mode and a Phase-Locked Loop, IEEE Transactions on Industrial Electronics, 2018, 65.2, 1097-1106.

[18] Guimaraes, J. S., de Almeida, B. R., Tofoli, F. L., and de Souza Oliveira, D., Three-Phase Grid-Connected WECS with Mechanical Power Control, IEEE Transactions on Sustainable Energy 2018, 9.4, 1508-1517.

[19] Krishnan, R., Electric motor drives: modeling, analysis and control, 2001, Prentice Hall.

[20] Conroy, J., and Watson, R., Torsional damping control of gearless full-converter large wind turbine generators with permanent magnet synchronous machines, Wind Engineering, 2007, 31(5), 325-340.

[21] Wang, H., Blaabjerg, F., Ma, K., and Wu, R., Design for reliability in power electronics in renewable energy systems-status and future, In 4th International Conference on Power Engineering, Energy and Electrical Drives, IEEE, Istanbul, 2013, 1846-1851.
[22] Bierhoff, M. H., and Fuchs, F. W., Semiconductor losses in voltage source and current source IGBT converters based on analytical derivation, In 2004 IEEE 35th Annual Power Electronics Specialists Conferenc, IEEE, 2004,4,2836-2842.

[23] MATLAB 2014, ThingSpeak Support Toolbox,version 2.2, MathWorks Internet of Things Team, The MathWorks, Inc., Natick, Massachusetts, United States.

[24] Ammous A., Ghedira S., Allard B., Morel H. and Renault D., Choosing a thermal model for electrothermal simulation of power semiconductor devices, IEEE Transactions on Power Electronics, 1999, 14.2, 300-307.

[25] Li, Y., Qi, F., Guo, H., Guo, Z., Xu, G., and Liu, J., Numerical investigation of thermal runaway propagation in a Li-ion battery module using the heat pipe cooling system. Numerical Heat Transfer, Part A: Applications, 2019, 75(3), 183-199.

[26] Qian, C., Gheitaghy, A. M., Fan, J., Tang, H., Sun, B., Ye, H., and Zhang, G., Thermal management on IGBT power electronic devices and modules. IEEE Access, 2018, 6, 12868-12884.

[27] Chen, H., Yang, J., and Xu, S., Electro-thermal Based Junction Temperature Estimation Model for Power Converter of Switched Reluctance Motor Drive System, IEEE Transactions on Industrial Electronics., 2019.

[28] Ravelo, B., Agnus, B., Carras, S., and Davin, T., Cauer Ladder Inspired Kron-Branin Modelling of Thermal 1D Diffusion, IEEE Transactions on Circuits and Systems II: Express Briefs, 2019.

[29] Busca C., Teodorescu R., Blaabjerg F.,Munk-Nielsen S., Helle L., Abeyasekera T. and Rodriguez T., An overview of the reliability prediction related aspects of high power IGBTs in wind power applications, Microelectronics Reliability, 2011, 51(9-11), 19031907.

[30] Wintrich, A., Nicolai, U., Tursky, W., and Reimann, T., Application manual power semiconductors, Semikron international $\mathrm{GmbH}$, 2011.

[31] Givaki, K., Parker, M., and Jamieson, P., Estimation of the power electronic converter lifetime in fully rated converter wind turbine for onshore and offshore wind farms., 7th IET International Conference on Power Electronics, Machines and Drives (PEMD 2014), Manchester, UK, 2014, (2-4).

[32] Liu H., Ma K., Loh P. C., and Blaabjerg F., Lifetime estimation of MMC for offshore wind power HVDC application, the 2014 International Power Electronics and Application Conference and Exposition, Shanghai, China, 2014.

[33] Liu H., Ma K., Qin Z., Loh P. C., and Blaabjerg F., Lifetime Estimation of MMC for Offshore Wind Power HVDC Application, IEEE Journal of Emerging and Selected Topics in Power Electronics, 2016, 4(2), 504-511. 